\title{
Iconografía de la vida cotidiana en Grecia
}

\author{
Iconography of the domestic life in Greece
}

\author{
Pilar González SerRano*
}

\begin{abstract}
RESUMEN
Frente a los monumentales vestigios de la civilización griega, que nos llenan de admiración, no deja de ser interesante el análisis de los espacios en los que vivieron sus gentes, así como el estudio de los humildes objetos de la vida cotidiana, ya que a través de ellos podemos comprender el día a día de un colectivo anónimo, gracias a cuyo esfuerzo se alcanzaron las cotas de civilización y cultura de las que nos dan testimonio sus magníficos restos

materiales: sus ciudades, sus templos, sus edificios públicos, gimnasios, teatros, etc.

El marco físico de la vivienda, así como el funcionamiento interno de la misma dentro del cual cada objeto cumplía con su adecuado cometido constituyen la base de una singular iconografía material, esencial para comprender la actividad doméstica de los griegos.
\end{abstract}

\section{PALABRAS CLAVE:}

Vida doméstica, la vivienda griega, el mobiliario griego, la cocina y las comidas griegas.

\begin{abstract}
Faced with the monumental remains of Greek civilization that fill us with admiration. it is interesting the analysis of the spaces where the people lived, and the study of the humble objects of everyday life of an anonymus collective, thanks to whose efforts were reached heights of civilization and culture which we witness the magnificent remnants: their citires, temples, public buildings, gymnasiums, theaters, etc. The physical framework of housing and the inner workings of it, within wich each subject served its proper purpose, form the basis of a singular iconography material essential for understanding the domestic activity of the Greeks.
\end{abstract}

\section{KEYWORDS:}

Domestic life; Grek housing; furniture Greek; cuisine and Greek food.

\footnotetext{
* Profesora Titular de la UCm. E-mail: pilar.a.gonzalez@gmail.com
} 
Frente a los monumentales vestigios que nos deslumbran y llenan el espíritu de admiración considerando los logros alcanzados por la civilización griega, no deja de ser interesante bajar a ras de tierra y dejar que los humildes objetos de la vida cotidiana nos lleven a comprender el día a día de sus gentes, un colectivo anónimo gracias a cuyo esfuerzo se alcanzaron las cotas de las que dan testimonio sus magníficos vestigios.

Como todos los pueblos mediterráneos de la antigüedad, los griegos fueron "consumidores del aire libre», es decir amigos de realizar sus actividades cotidianas fuera de casa. Estaban acostumbrados a pasar sus jornadas en el Ágora, en las escalinatas de los templos, en el campo, en los talleres, en los puertos, etc. En consecuencia, las clases populares no pusieron un afán especial, dada su economía, en la calidad de sus viviendas. La belleza y la armonía se reservaban para los templos de los dioses y para los edificios públicos, orgullo de las ciudades que crecían en su entorno.

Sin embargo, examinando los restos domésticos, podemos seguir, con todo detalle, el desarrollo de la vida diaria de quienes fueron, en definitiva, los verdaderos protagonistas de la civilización griega.

\section{LA VIVIENDA}

En términos generales, puede decirse que las casas griegas fueron sencillas estancias dispuestas en torno a un patio central, cerradas al exterior y situadas a lo largo de calles y callejuelas, sin tener en cuenta más criterios urbanísticos que la disposición del terreno, la economía de la construcción y la protección de los vientos. Eran, en su mayoría, humildes viviendas en las que se hacinaban todos los miembros de la familia, sin exigir más que un buen cobijo para dormir, comer, apilar leña y albergar a algunos animales que asegurasen su básico alimento.

En las habitadas por gente más acomodada, ya de mayores dimensiones, el espacio disponible se repartía según determinadas normas y costumbres La mejor estancia, situada en la zona más retirada, era la del hombre de la casa, el llamado «androceo». Cerca de ella solía estar, también, el dormitorio conyugal, aunque el ama de casa hiciera su vida en el denominado "gineceo", la zona de estar destinada a la crianza de los niños y a la realización de los trabajos femeninos como el hilado, confección de ropa, etc. En las habitaciones más secas se almacenaba el grano, en las más frescas el vino, y en la más cercana al patio, la cocina para facilitar la salida de humos, aunque era muy frecuente que se guisase en el propio patio. Las necesidades domésticas que con el tiempo se iban generando en cada núcleo familiar, determinaron, en definitiva, que las dependencias de las viviendas creciesen de modo anárquico para adecuarse a ellas de modo utilitario y práctico.

Generalmente las casas griegas se orientaban al mediodía o al poniente para aprovechar lo más posible los beneficios del sol. La parte norte, la más 
fría, se destinaba a la conservación de los alimentos y a las estancias previstas para soportar los calores del verano. Era costumbre disponer en alto el sector sur y, a ras de suelo, el norte. Se creaban, así, los dos ambientes clásicos de las viviendas del área mediterránea: la «solana» y la «umbría», patrón respetado hasta hace pocos años en las llamadas casas solariegas o de labor. Construidas con materiales pobres, solían tener una o dos plantas y una sola entrada. Habría que esperar a que las reformas urbanísticas de Hipódamo de Mileto ${ }^{1}$ se generalizasen en época helenística para encontrar barrios con trazado reticular, ubicados generalmente en las afueras de las poleis, donde se construyeron casas lujosas para las gentes pudientes, con amplios aposentos y cuidados peristilos. Con el tiempo, las casas aumentaron el número de habitaciones y llegaron a tener dependencias de gran empaque, como fue el mégaron con hogar lateral o central, destinado a las reuniones del señor de la casa. Los esclavos dormían todos en el patio o en uno de los pajares, sin tener una estancia preparada específicamente para su alojamiento.

Del funcionamiento casero se ocupaba la mujer, la llamada «esclava en el trono» en el decir ateniense, por ser la jefa del hogar. De ella dependía el avituallamiento del mismo (aunque la compra solían hacerla los hombres), la vigilancia de de los telares y la crianza de los hijos. Era en definitiva la experta «ecónoma» del clan, pero totalmente sometida al varón y apartada del mundo exterior, al que no se le concedía el menor acceso. Con todo, la buena gestión de la vida familiar fue muy valorada cuando se desempeñaba con eficiencia, ya que la prosperidad de las ciudades dependía, en gran medida, en la estructura familiar.

Muy criticadas fueron, en cambio, las mujeres que no cumplían con su trabajo, y muy desdichados se declaraban los hombres que no tenían una esposa dispuesta y trabajadora que les facilitara su vida de «gandul doméstico», el mismo que recomendaba: si has acertado con tu primera mujer, alégrate de tu fortuna, de lo contrario es una locura probar con otra. En los tiempos actuales, hay que reconocer el gran mérito que tenían las mujeres hacendosas, ya que lo daban todo sin recibir, a cambio, el menor reconocimiento.

El elogio más cumplido que una mujer griega recibió de su marido es el que figura en un célebre epitafio: fue casta, hiló la lana, tuvo cuidado de la casa. Con tal testimonio, fácil es comprender lo que fue su vida en una sociedad en la que prácticamente no tenía ninguna representatividad oficial. Sin embargo, gran parte de los sencillos y numerosos objetos ligados a su actividad son los que han llegado hasta nosotros y, gracias a ellos, podemos reconstruir una iconografía de los objetos que utilizó para hacer agradable la vida familiar.

1 Hipódamo de Mileto, fue un famosos arquitecto griego del siglo V a.C. inventor de la planimetría ortogonal o reticular de las ciudades. A petición de Pericles, trazó la planimetría de Thurium (en el emplazamiento de la antigua Sibaris, en la Lucania), y del barrio portuario del Pireo, en Atenas. 


\section{EL SUMINISTRO DEL AGUA}

El primer problema para el desenvolvimiento de la vida cotidiana era la falta de agua. Muchas casas no tenían ni siquiera pozo, por lo que el primer cometido diario era el abastecimiento del preciado líquido en las fuentes públicas. Por lo general esta tarea corría a cargo de las muchachas o esclavas más jóvenes que, provistas de sus hidrias, vasijas de tres asas, propias para dicho menester, acudían las veces que fuera necesario para conseguir llenar las grandes tinajas de la casa. Este ir y venir se convirtió, con el tiempo, en un trajín lleno de connotaciones galantes, ya que gracias tales salidas justificadas, las mujeres se dejaban ver por sus pretendientes y ellas podían, a su vez, establecer con ellos tímidos escarceos. Esta costumbre se mantuvo en uso en las sociedades agrarias por largo tiempo, llegando incluso en muchos pueblos hasta mediados del siglo XX. La fuente se convertía, al caer la tarde, en un lugar de encuentro entre mozas y mozos, como recuerdan, sin ir más lejos, alguno de nuestros más pícaros refranes: Tanto va el cántaro a la fuente....

Existían los baños públicos, pero eran lugares no frecuentados por las clases pudientes: a los baños va el pueblo, no los insignes hacendados- decían los griegos. Normalmente los ciudadanos ricos se bañaban, aunque sin excesiva frecuencia, en sus casas. Como brazo de ducha se utilizaba el del esclavo de turno que, subido sobre un banquillo y provisto de un lutrophóros dejaba caer el agua sobre el cuerpo del bañista, que se mantenía de pie dentro de una tina de cerámica o metal. Tan singular recipiente, provisto de un agujero en su fondo, se colocaba sobre una especie de desagüe que canalizaba la salida del agua hasta la fosa general de vertidos, sita en la cocina o en una dependencia destinada a tal fin.

\section{LOS SERVICIOS HIGIÉNICOS}

Por lo que se refiere a los servicios higiénicos, la solución era muy primaria. En el patio, en un lugar semiescondido, había una especie de gran orinal, metálico o de cerámica, el amis, destinado a servir de «inodoro» cuando era preciso, ya que, en la mayoría de los casos las urgencias se resolvían a «pleine nature». Tal artilugio, se conectaba también con el canal de desagüe al que ya hemos aludido. Para los niños existían unos orinales especiales donde se les dejaba sentados por largos ratos para acostumbrarles a regular sus deposiciones. Escenas en las que se recogen tales momentos se reflejaron en la decoración de los vasos cerámicos.

\section{LA ILUMINACIÓN}

Otro de los importantes problemas de las casas era la iluminación, que se resolvía por medio de antorchas formadas por humeantes haces de maderas resinosas, dispuestas en antorcheros (lampadarios) o en candelabros de bocas múltiples, para ampliar con la multiplicidad de puntos lumínicos el efecto que requerían 
las grandes estancias. Asimismo se usaban candiles de cerámica o de bronce, en cuyo fondo, relleno de aceite, ardían los pabilos, y candelas de cera. Estos eran muy numerosos en todas las casas ya que conformaban el sistema manual e individual del que se valían sus moradores para alumbrarse en sus desplazamientos por las distintas habitaciones.

Por otro lado, hay que recordar que la iluminación natural, la del sol, fue la más importante y aprovechada en función de la sabia orientación de las habitaciones más vividas de la casa, siempre dispuesta de cara a oriente y a poniente, como ya se ha dicho.

\section{EL MOBILIARIO}

Los muebles de una casa de clase media eran, como decía Jenofonte, muebles adecuados para locales adecuados. Siguiendo este criterio había que contar con los destinados al servicio y a la custodia de las ropas y de los objetos de valor. Entre los primeros se encontraban las mesas, sillas, sillones, taburetes, camas, divanes, lampadarios, etc. y, entre los segundos los arcones, los cofres y las cajitas metálicas o cerámicas de tocador. A todo esto hay que añadir el menaje de cocina, compuesto por calentadores de mesas, cazuelas, pucheros, sartenes, soperas, platos, fuentes, cuencos, etc.

De todo este conjunto nos han quedado numerosos vestigios, tanto materiales, como relivarios y pictóricos. Entre estos últimos destacan las maravillosas cerámicas áticas en las que no sólo se representaron toda clase de episodios mitológicos, teatrales o gimnásticos, sino también escenas de la vida cotidiana. En ellas la presencia del mobiliario y de los objetos más comunes nos ha permitido conocer su tipología y usos.

La habitación más importante, ya se ha dicho que era la conyugal en la que había una cama de matrimonio, muy distinta a las simples yacijas en las que dormían los esclavos y jóvenes de la casa. Sobre cuatro sólidas patas de madera, a veces talladas en su parte superior, a guisa de capitel, se colocaba el «somier» formado, por lo general, por fuertes correas de cuero. Sobre él se colocaba un colchón relleno de lana o de plumas. Con los cobertores y cojines, hechos con lujosas piezas de tela de variado colorido o de pieles de animales, se enriquecía el aspecto del lecho. De estructura similar eran los divanes que se utilizaban en los banquetes, ya que a ellos los griegos asistían recostados, teniendo a su alcance una mesita en que se colocaban los alimentos y las copas.

Como complemento obligado de dicha habitación matrimonial estaban los arcones en los que se guardaban las ropas. Entre las mismas, siguiendo viejas costumbres, se colocaban frutas olorosas tratadas de forma tradicional. En los cofres con cerradura se custodiaban las monedas y los objetos de valor. Los lampadarios, los regalos de boda de cierto valor estético y material, como los llamados lebetes gamikós, junto con algunas mesitas venían a completar el mobiliario de dicha estancia principal o de respeto. 
En todas las casas había una gran variedad de sillas y mesas (algunas plegables), de diferentes formas y tamaños. Algunas de estas piezas eran muy lujosas y otras muy sencillas. Era el mobiliario más utilizado, el que se trasladaba de un lugar a otro creando, en cada caso, el ambiente adecuado para las más elementales necesidades de la vida diaria. Los materiales de construcción para estos muebles fueron principalmente el cuero y la madera.

\section{JOYAS Y OBJETOS PERSONALES DE TOCADOR}

Capítulo especial en el contexto de la vida cotidiana y sobre todo por lo que se refiere al ámbito femenino, son las joyas y objetos de tocador llegados a nosotros. Tales vestigios demuestran el buen gusto de los artífices y orfebres griegos, así como el de sus usuarias. Las pixidas, lekanidas, alabastrones, aribalos son vasos cerámicos asociados al mundo femenino. Los espejos de metal bruñido y los peines de marfil son otras muestras del refinamiento de la época.

El día de gloria de una mujer era el de su matrimonio y de dicha fecha conservaba parte del ajuar que había traído de casa de sus padres, los regalos recibidos por familiares y amigos, así como los que le había ofrecido su propio marido. La mayoría de tales recuerdos, sobre todo las joyas, aderezos y perfumes, poblaron su mundo, estando guardados en esas pequeñas cajitas, a las que hemos hecho mención, y que nos sorprenden por su exquisitez y fragilidad desde las vitrinas de muchos museos. Muy valoradas por la mujer griega, suelen aparecer entre sus manos en muchas de las estelas funerarias griegas en las que se sugiere la despedida de la difunta no sólo de la vida, sino también de cuanto se ha amado².

Colecciones como la de Elena Stathatos que se conserva en el Museo Arqueológico Nacional de Atenas, así como otra magnífica del Museo Metropolitano de Nueva York, demuestran el grado de refinamiento alcanzado por los orfebres griegos desde la época más remota hasta el período bizantino. El hecho de que la mujer luciera aderezos de alto precio redundaba en el prestigio personal del marido y acreditaba su posición social.

\section{LA COCINA}

La compra la realizaban los hombres quienes acudían diariamente al ágora, acompañados del agorastés, es decir del esclavo encargado de cargar con el peso de los productos adquiridos. Entre ellos se encontraban las habas, frescas si la estación lo permitía o, de lo contrario, secas para hacer puré, para tostarlas o, a veces, para molerlas y hacer harina, las lentejas, los garbanzos, las judías, desgranadas o en vaina. Se consumían también con profusión las hortalizas y una

2 González Serrano, P., «Las estelas del adiós», en la revista Más cerca de Grecia, Madrid, 1990, no 5 , pp. 89-95. 
gran variedad de verduras que se condimentaban al servirlas a la mesa con vinagre y plantas aromáticas. Las más demandadas eran las lechugas, las zanahorias, la achicoria, los nabos, los espárragos, las coles, las cebollas y los ajos. Muy apreciadas fueron también las raíces de los asfódelos (gamones) que se cocían bajo las cenizas y se sazonaban con sal y aceite. Entre los frutos destacaban los higos, tanto tiernos como secos. Se contaba, asimismo, con toda clase de quesos ya que la leche, como el vino y la harina eran productos de primera necesidad. "Comedores de harina» había llamado Homero a los hombres y fue bien cierto que para los atenienses del siglo $\mathrm{V}$ a.C. el trigo se convirtió, junto con la cebada, en el alimento básico de su sustento.

Tanto si el pan se cocía en casa como si se compraba ya hecho al panadero, el tipo más difundido fue la maza, una torta de harina de cebada cocida al horno con diversos tipos de sabor, según el líquido con el había sido amasada. El pan redondo, de verdadero trigo, artos, se reservaba para las fiestas. No se podía obtener a diario y que había que pagarlo a buen precio, dado que la harina de trigo escaseaba en Atenas.

La mujer, ayudada por las esclavas, era la encargada de guisar. Pocos griegos contaron en sus casas con un cocinero (mágheiros), como sucedió después en época helenística y en el mundo romano, por lo tanto, puede decirse que la cocina griega fue eminentemente casera y sencilla. Se consumían muchas verduras, hasta el punto de que los griegos se calificaban a sí mismos como «phyllotroghes o comedores de hojas» El pescado era tan habitual en las comidas que se llamaba simplemente «condumio» (opson, psarı). También se comía toda clase de crustáceos y moluscos, así como las anguilas de agua dulce, siendo famosas las del lago Copais. En cuanto a la carne se refiere, es de notar que la de buey fue la más apreciada en los tiempos más antiguos, siendo menos valoradas las de cordero, de cabra y de ciervo. Sin embargo, se acabó prefiriendo la del magro de cerdo y la de los lechoncillos. Se aconsejaba sobre todo en las dietas de los atletas, como el alimento más digerible y nutritivo. Se tenía por más sana que la del buey, aunque en la antigüedad hubiera sido ésta la preferida. Tal vez las advertencias de los hipocráticos acerca de los males que comportaba la ingesta de la carne de buey, hicieron cambiar los usos de su consumo. A veces se recurría a la carne de cerdo ya preparada por el efthopolés. Asimismo se comían muchas salchichas, sobre todo en las Apaturias, fiestas de las fratrías celebradas entre octubre y noviembre.

La carne más a mano fue siempre la de caza, siendo la más valorada la de la liebre. Manjares frecuentes en la mesa fueron los pavos reales, los faisanes, los patos, las ocas, las codornices, los tordos, etc.

Sólo en los banquete, simposia, se hacían ciertos excesos y se consumían vinos de calidad, como los de Rodas, de Quíos, de Lesbos y de Taso, aunque siempre rebajados con agua y edulcorados con miel. Estos vinos se conservaban en ánforas dispuestas en los bancales de arena de las bodegas o mantenidas por unos pies de hierro llamados incitegas La citada mezcla se realizaba en las crateras (así llamadas por contener vino, krasi), se servía en los enocoes (jarras de boca trilobulada) y se bebía en las cílicas o cálices. 
Existían todo tipo de cazos, cazuelas y sartenes. Se cocinaba en hogares de leña en los patios exteriores, asándose las carnes en parrillas y espetones. Las comidas se mantenían calientes por medio de unos hornillos de leña en los que se asentaban los recipientes con la comida ya hecha y sazonada.

\section{LAS COMIDAS}

En tiempos de Homero la primera comida se llamaba áriston, la segunda déipnon y la tercera dórpon. En época de Pericles la primera se conocía con el nombre de akrástima (de ákratos vino puro en el que se mojaba el pan); luego venía el áriston, la comida del mediodía, semejante al prandium romano; Se preparaba cuando el hombre de la casa volvía del mercado con los víveres adquiridos. Por último estaba el déipnon o cena, la comida más importante del día. Comenzaba al anochecer y podía durar hasta bien entrada la noche. A ella se solían incorporar invitados y familiares.

Eran frecuentes las asociaciones tales como el éranos o thíasos, grupos que se reunían para cenar aportando cada comensal lo que habían preparado en su casa. Esta costumbre todavía se conserva en parte de nuestro levante español. Son las cenas al aire libre, llamadas «de sobaquillo» porque cada uno de los comensales acude con lo que tiene disponible, bajo el brazo.

El ceremonial de las cenas de aparato corría a cargo del trapezopoiós o trapezonomós. La mujer se quedaba en la sombra, no pudiendo participar en las mismas. Tan sólo se admitía su presencia en los convites de boda. En cambio si asistían las cortesanas o hetairas que animaban el convite con su música.

Antes de comer, se lavaban las manos en una jofaina, ya que comían con los dedos, y se limpiaban con migas de pan que luego echaban a los perros. Tales encuentros tenían algo de sagrado por lo que eran frecuentes las libaciones a los dioses.

En el mundo de los simposia participaban, en algunas casas distinguidas, los filosofos y pensadores más conspicuos de la sociedad. Sus discusiones eran famosas y dieron lugar a célebres diatribas, muchas de las cuales han llegado hasta nosotros en forma de diálogos. Los hombres eran los que debatían disfrutando de manjares cocinados 0 , al menos, dispuestos por manos femeninas que siempre se quedaban entre las sombras.

\section{BIBLIOGRAFÍA}

ALLEN, K., One day in ancient Greece, Londres, 1974.

CARR RIDER, B., The Greek House, Cambridge, 1965.

FINLEY, M. I., Los griegos de la antigüedad, Barcelona, 1994.

FLACELIĖRE, R., La vida cotidiana en Grecia en el siglo de Pericles, Buenos Aires, 1959.

LÓPEZ MERLO, R., Así vivían en la Grecia antigua, Madrid, 1994. 


\section{RELACIÓN DE FIGURAS}
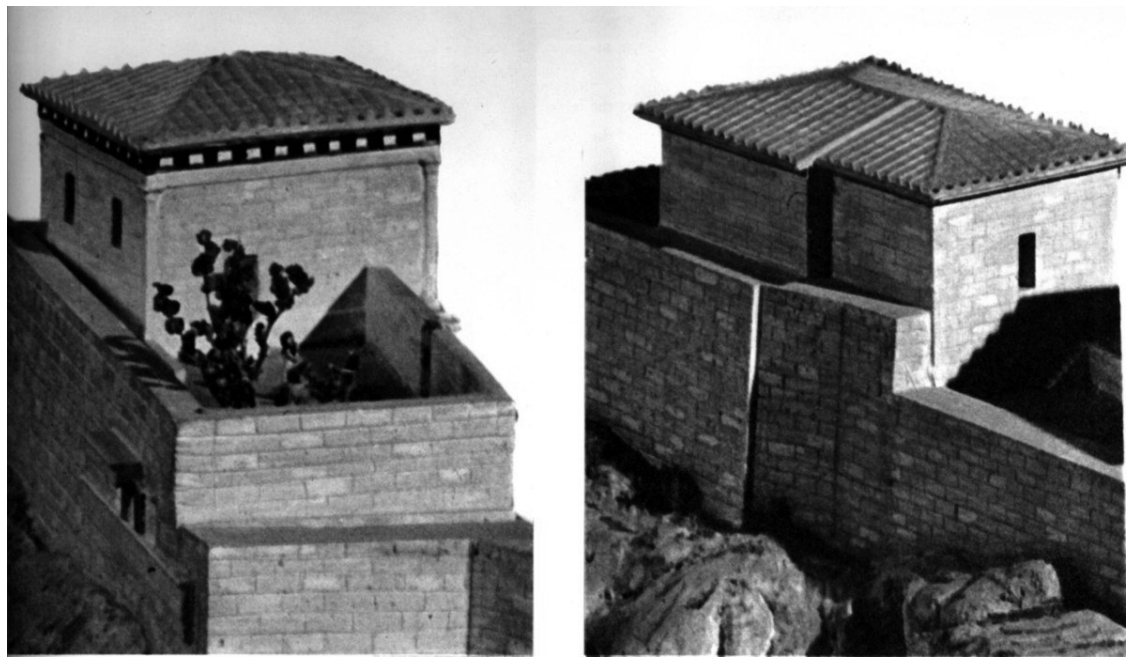

Fig. 1. Viviendas típicas de la época clásica con su pequeño jardín. Maquetas en el Royal Ontario Museum de Toronto.

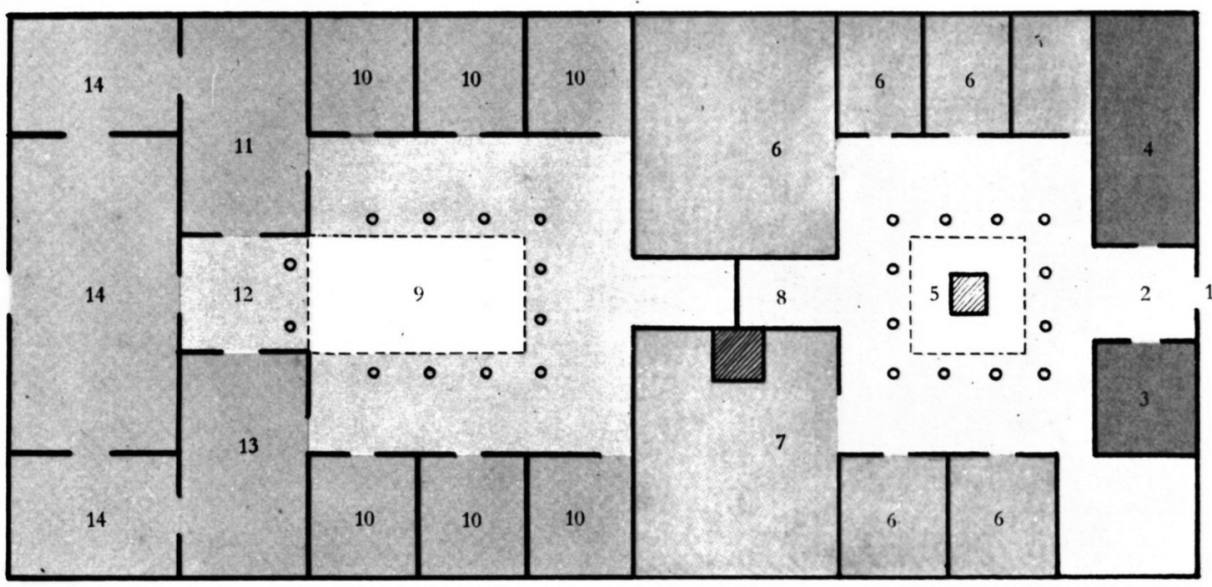

Fig. 2. Planta de la casa griega en época tardía: 1. Puerta. 2. Atrio. 3. Habitación del portero. 4. Establo. 5. Patio con peristilo. 6. Habitaciones para hombres, androceo. 7. Mégaron con el hogar. 8. Cancela del gineceo. 9. Peristilo del gineceo. 10. Habitaciones para mujeres. 11. Habitación conyugal. 12. Habitación abierta. 13. Habitación de las hijas. 14. Habitación de diversos usos. 15. Puerta del pasillo. 
Fig. 3. Típico pozo ateniense de piedra o de mármol. Estaba enterrado en el suelo hasta la embocadura. Museo del Ágora.

Atenas.

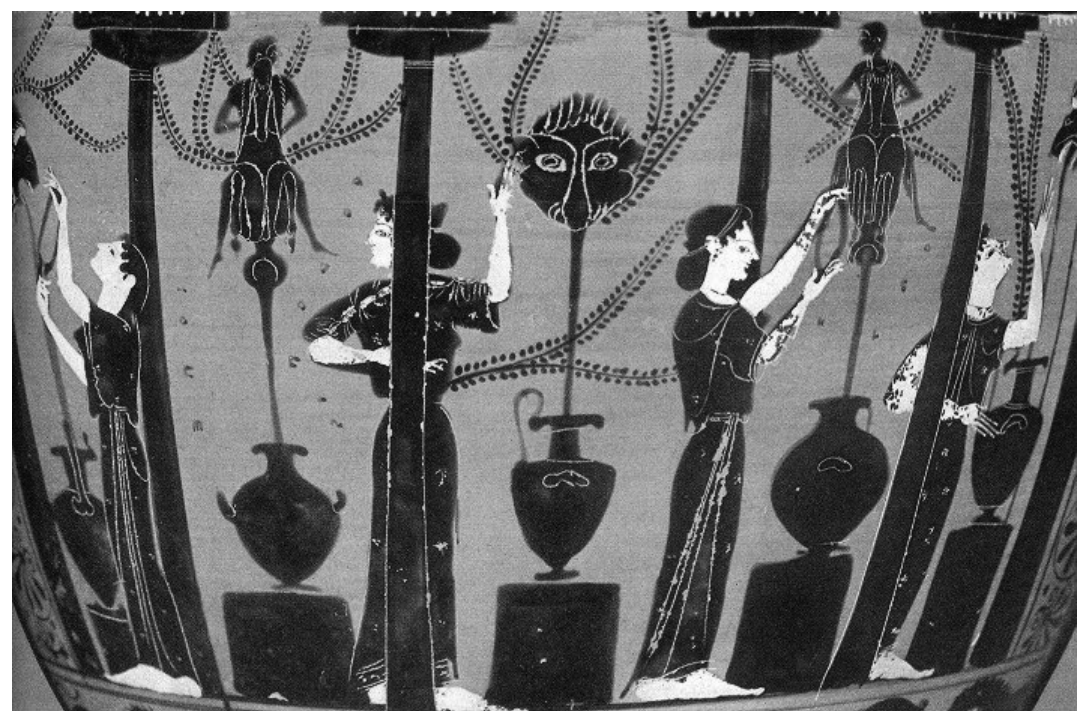

Fig. 4. Mujeres en la fuente. Vaso ático de figuras negras. Siglo VI a.C. Museo de Villa Giulia. Roma. 


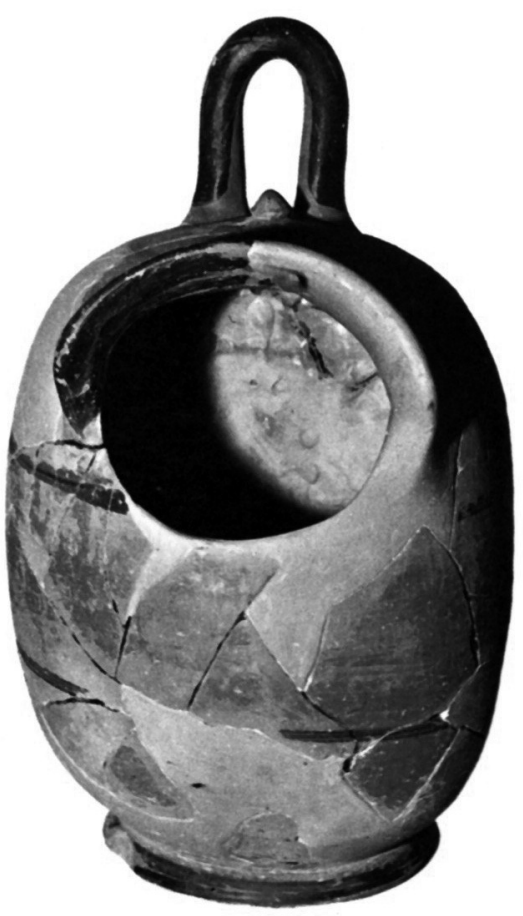

Fig. 5. Amis. Podía ser de terracota o de metal. Museo del Ágora. Atenas.

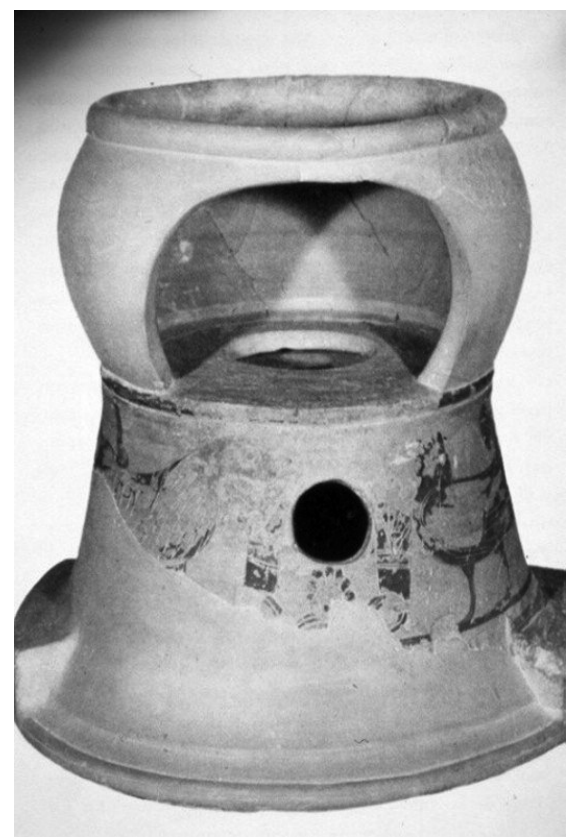

Fig. 6. Amis infantil. Terracota. Museo del Ágora. Atenas. 
Fig. 7. Silla (klismós) y escabel. Reconstrucción de Saridis a partir de la Estela de Hegeso. Museo Arqueológico Nacional de Atenas.
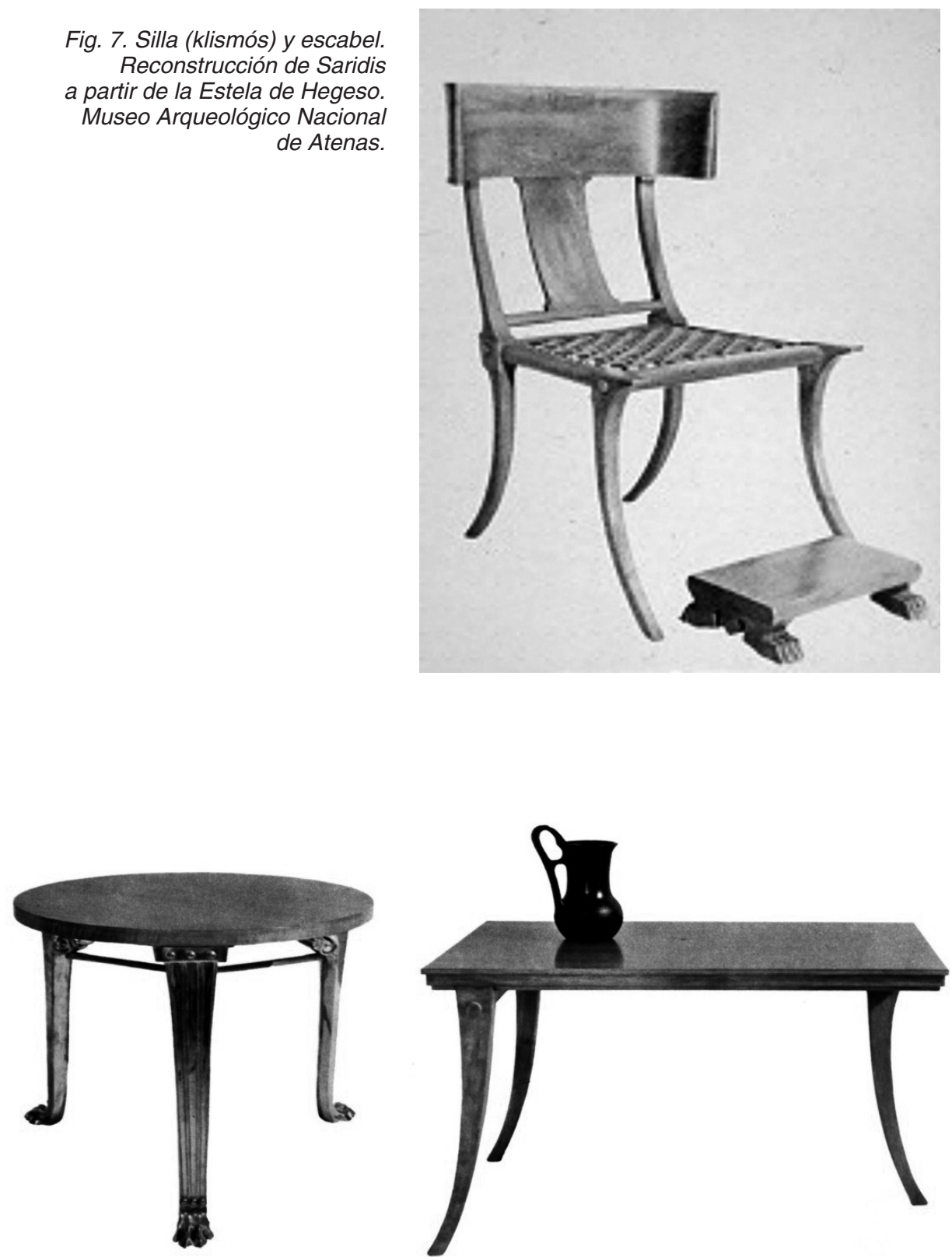

Fig. 8. Mesas de tres patas usadas en los banquetes. Reconstrucciones de Saridis. Museo Arqueológico Nacional de Atenas. 


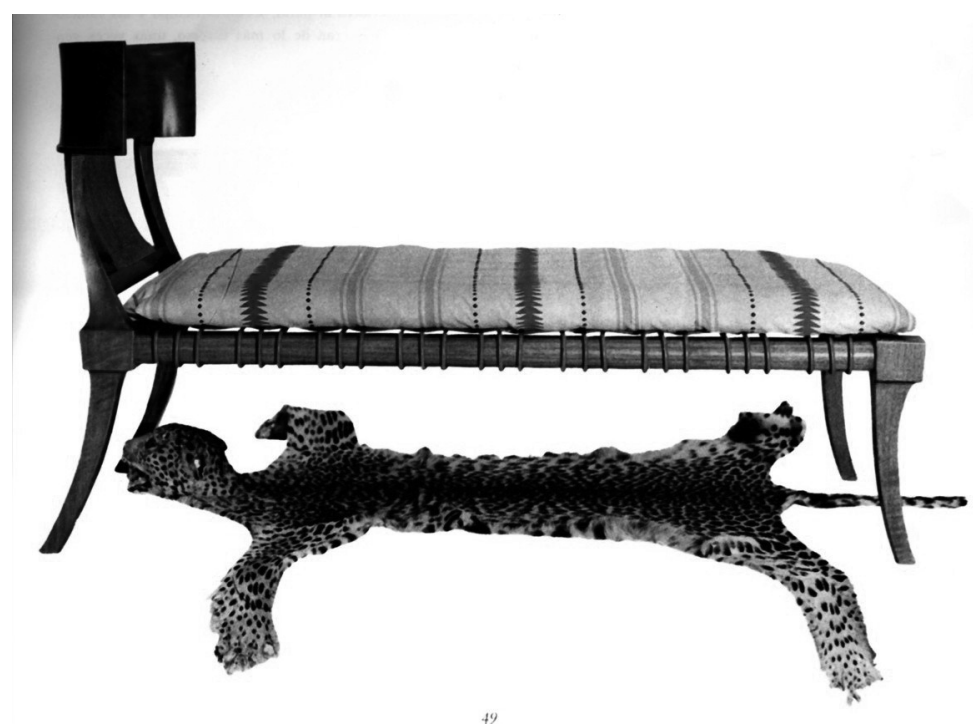

Fig. 9. Diván de banquete y piel de animal usada como alfombra. Reconstrucción de Saridis. Museo Arqueológico Nacional de Atenas.

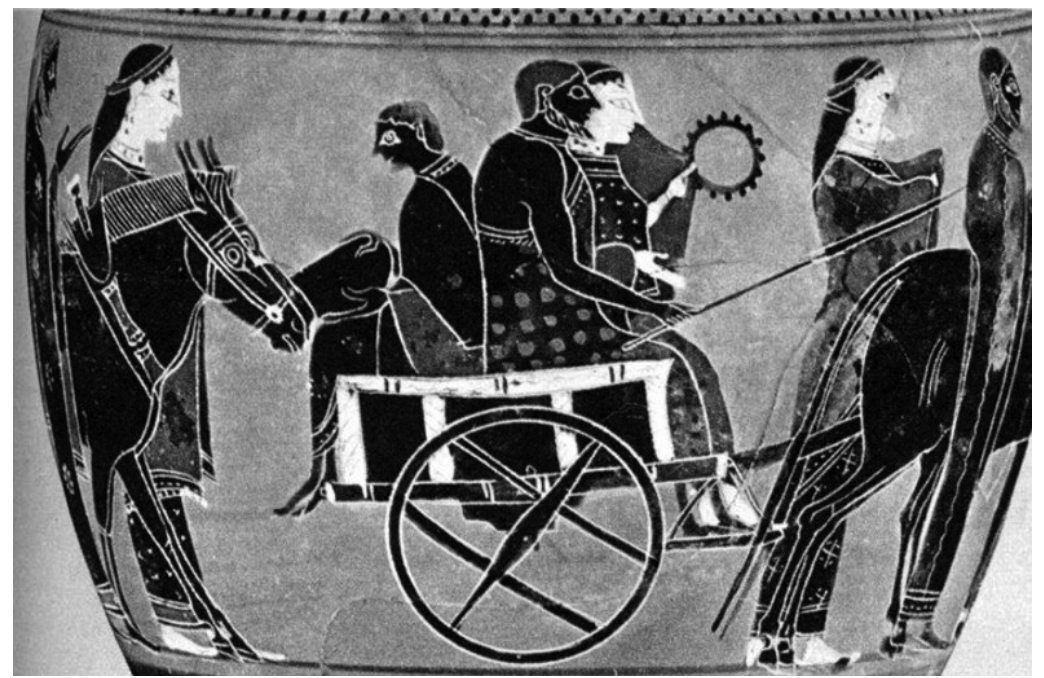

Fig. 10. Cortejo nupcial. Detalle. Lekito. Pintor de Amasis. \pm 550 a.C. Metropolitan Museum of Art de Nueva York. 


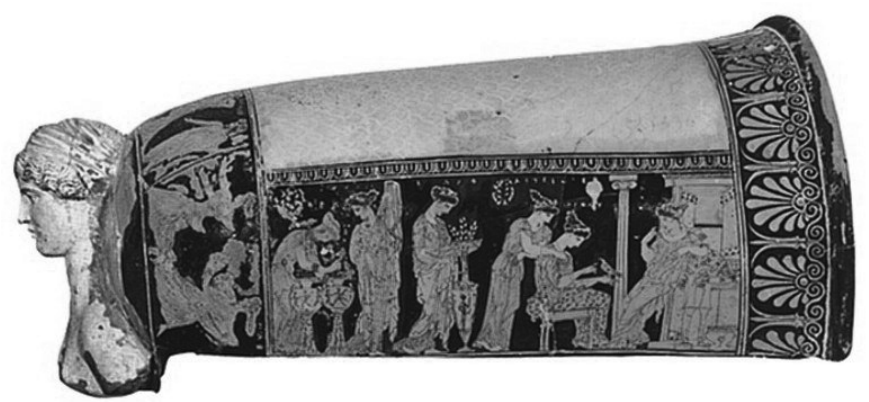

Fig. 11. Epinetron de Eretria. Preparativos de la boda de Alcestis. Atribuido al «Pintor de Eretria». 425 a.C. Atenas. Museo Nacional.

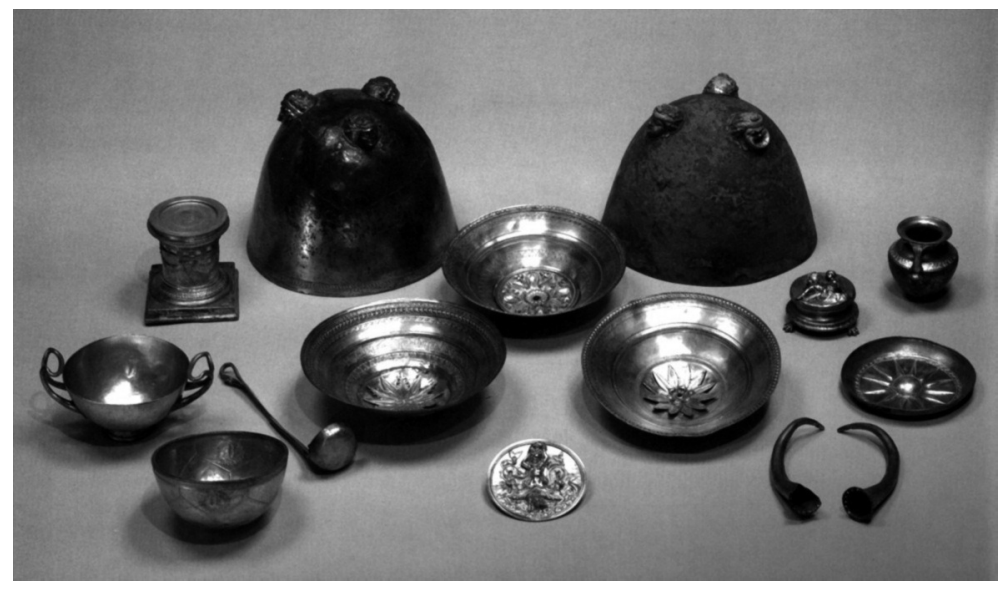

Fig. 12. Vajilla de oro y plata. Siglo III a.C. Museo Metropolitano de Nueva York.
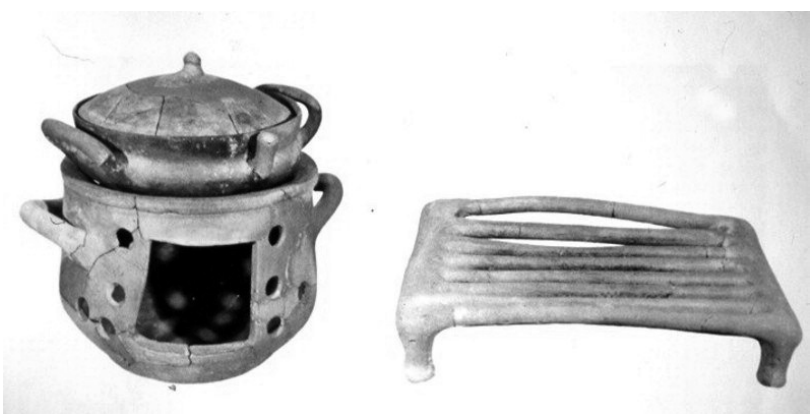

Fig. 13. Horno y sopera. Museo del Ágora. Atenas. 


\section{Iconografía de la vida cotidiana en Grecia}

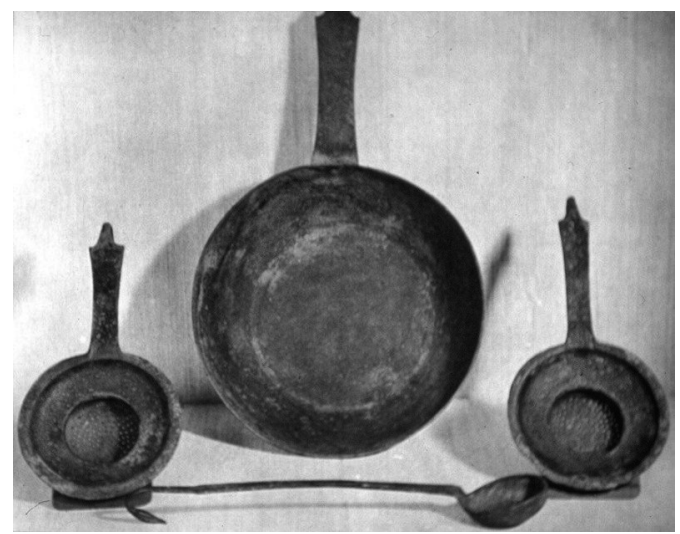

Fig. 14. Sartén, espumaderas

y cucharón.

Museo Benaki. Atenas.

Fig. 15. Vaso ático de figuras rojas. Eufronio. Alfarero y pintor. 1a mitad siglo $V$ a.C. Banquete. Juego del Kótabo. Museo Arqueológico Nacional de Atenas.

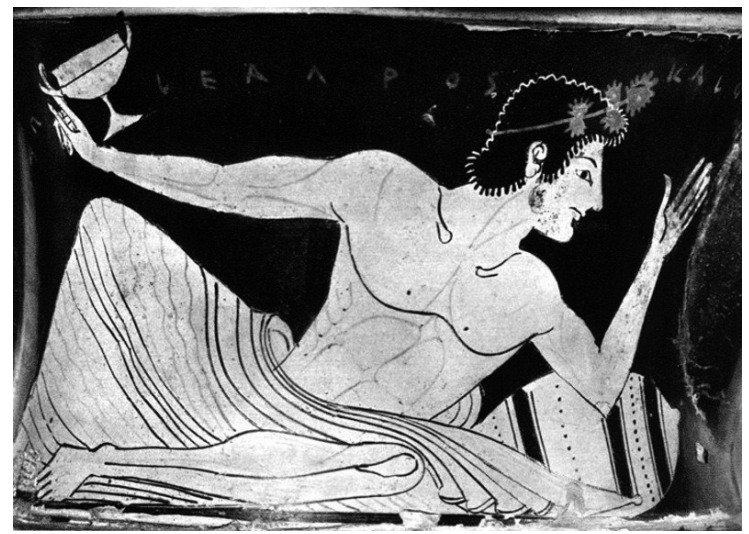

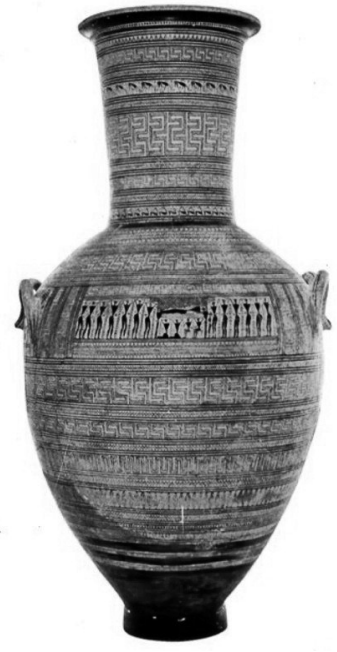

(C) UNED. Espacio, Tiempo y Forma Serie II, Historia Antigua, t. 24, 2011
Fig. 16. Ánfora del Dipylón. Escena funeraria. Siglo VIII a.C. Museo Arqueológico Nacional de Atenas. 
Fig. 17. Naiskos funerario, de la familia Proclides Aegilieos, de su mujer Arquipe y de su hijo Procles. Procede del Cerámico. Siglo IV a.C. Museo Arqueológico Nacional de Atenas.
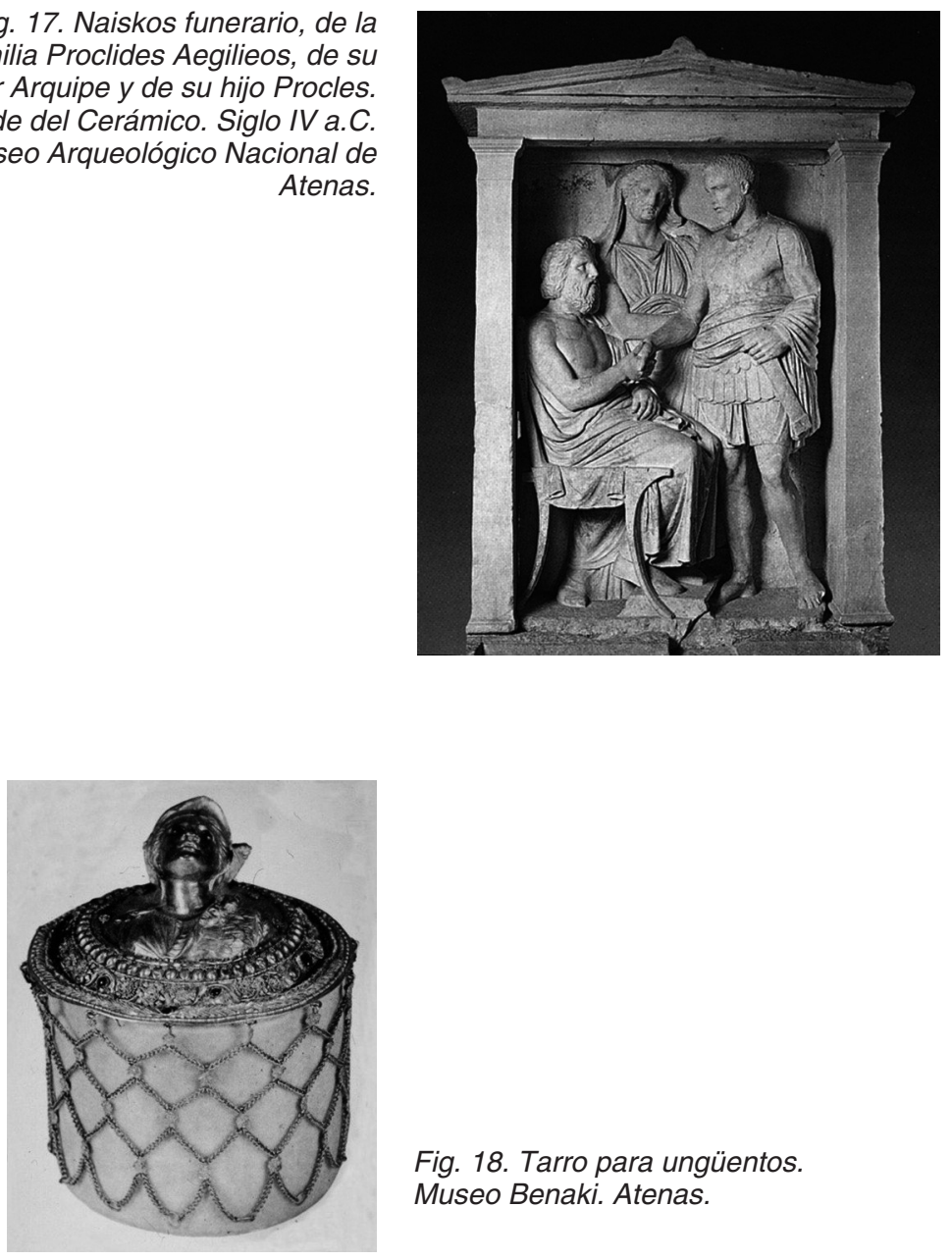

Fig. 18. Tarro para ungüentos. Museo Benaki. Atenas.

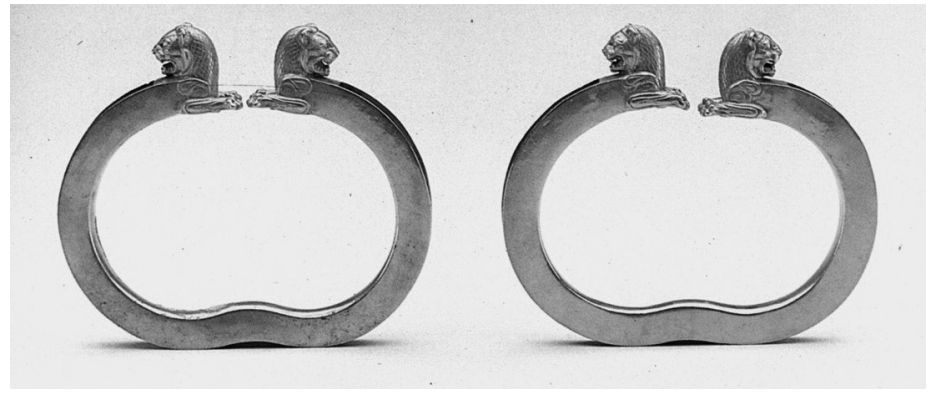

Fig. 19. Brazaletes de inspiración oriental. Finales del siglo VI a.C. Oro. Longitud: $9 \mathrm{~cm}$. Museo Metropolitano de Nueva York. 


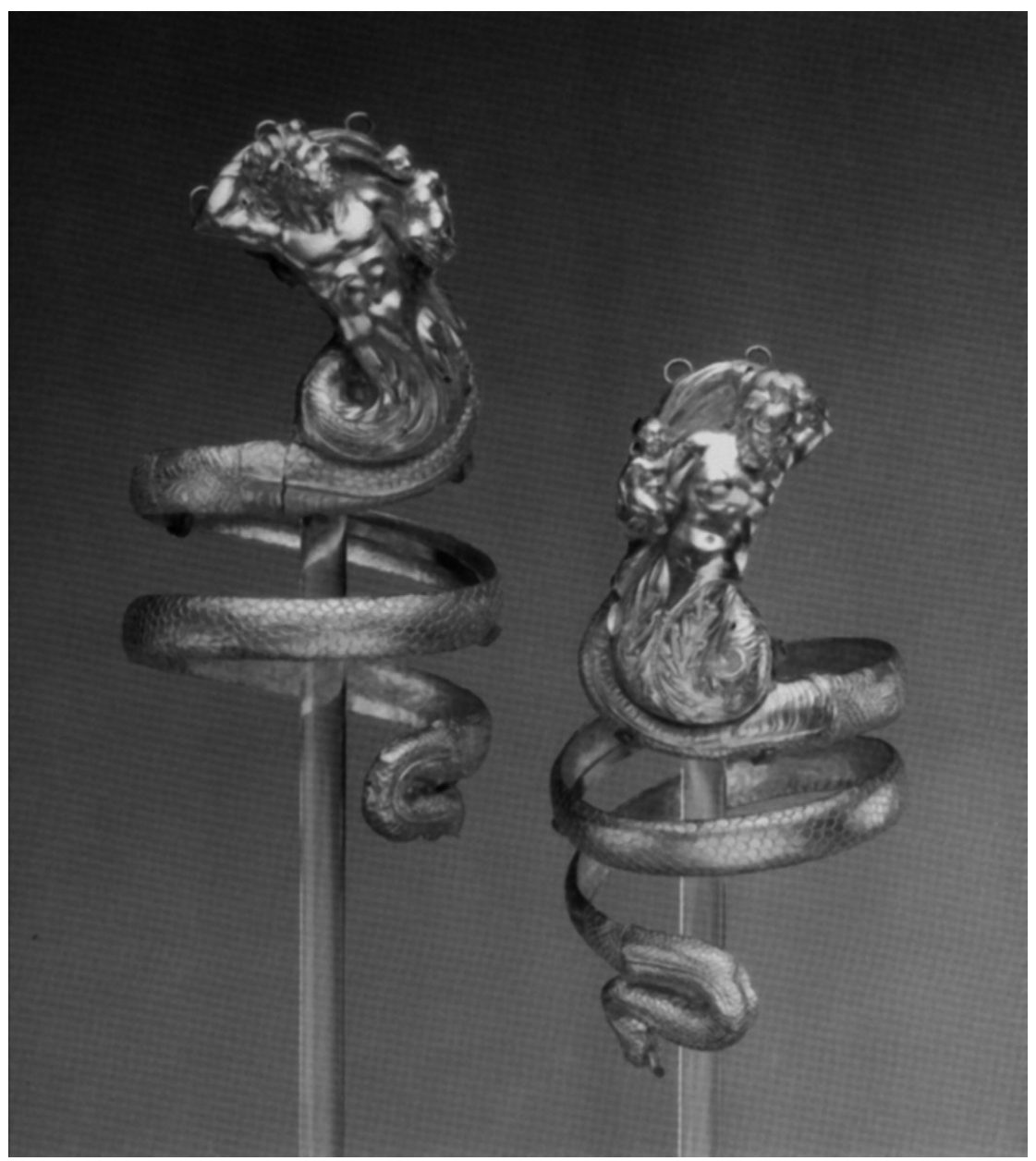

Fig. 20. Brazaletes de oro en forma de espiral rematados por un tritón y una tritonisa, ambos con un Eros en sus brazos. Siglo III a.C. Museo Metropolitano de Nueva York. 
17-GONZALEZ SERR 18/09/2012 14:35 Página 348 